\title{
Teaching Social Skills Students with Learning Difficulties and Behavioral Problems in the Inclusive Classroom
}

\author{
Alexandratos George ${ }^{1, *}$, Alexandratou Varvara ${ }^{2}$ \\ ${ }^{1}$ Vergotis str, Argostoli, Kefalonia, Greece \\ ${ }^{2}$ 43a D. Moutsopoulou str, Piraeus, Greece \\ *Corresponding author: alexang60@gmail.com
}

Received October 27, 2014; Revised December 12, 2014; Accepted December 28, 2014

\begin{abstract}
Systematic and multiple studies (Hackett, et all, 2010, Schnitzer, Andries, \&Lebeer, 2007), have shown that learning disabilities are a complex problem and beyond the effects on the cognitive-learning sector, may adversely affect the emotional and social development of children. Students with learning difficulties feel emotional distress in accordance to particular difficulties. Generally, they tend to have more emotional problems, low selfesteem, depressive symptoms, feelings of loneliness, anxiety, aggression and present social withdrawal compared to peers who do not have learning difficulties (Casserly, 2013). The contribution of education in addressing social adjustment problems faced by children with learning disabilities is essential. The method of intervention that a child may follow (a child) in school or special education, must have the support and active participation of parents (Broomhead, 2014). In our study we intend to present evidence showing the importance of research in the teaching of social skills through a program adressed to a student with learning disabilities and behavioral problems. We will also investigate the relationship between behavioral problems and difficulties in writing. The methodology comprises quantitative and qualitative data. The tools for qualitative data collection are the observation (through informal educational assessment), the intervention (with the form of didactic interaction), the Individual Structured Integrative Program of Special Education and the semi-structured interview. The tools for quantitative data collection are the experiment, the questionnaire with close-type questions which was filled by 20 students and the questionnaire with Likert questions which was filled by 20 adults.
\end{abstract}

Keywords: learning disabilities, behavior problems, inclusive classroom, Basic skills checklists

Cite This Article: Alexandratos George, and Alexandratou Varvara, "Teaching Social Skills Students with Learning Difficulties and Behavioral Problems in the Inclusive Classroom." American Journal of Educational Research, vol. 2, no. 12 (2014): 1284-1287. doi: 10.12691/education-2-12-24.

\section{Introduction}

In a study (Swinson, 2008) have shown that students with learning difficulties feel emotional distress in accordance to the particular difficulty. Generally, they tend to have more emotional problems, low self-esteem, depressive symptoms, feelings of loneliness, anxiety, aggression and present social withdrawal compared to peers who do not have learning difficulties (Casserly, 2013). Specifically, emotional problems and problematic behavior due to intrinsic causes can be integrated into two broad groups: a) internalized and b) the externalized problems. Syndromes such as: a) anxiety-depression, b) withdrawal-depression and c) somatic complaints can be categorized in internalized problems and syndromes as a) compliance with rules and b) aggressive behavior can be categorized in externalized problems (Achenbach \& Ndetei, 2012).

The external factors affecting the existence of emotional problems have to do with both the family environment and the school environment. It should be noted that due to the reduced school performance, children with learning difficulties may experience rejection in the school environment, both by peers and by teachers, as well as rejection by their parents, and that the problematic behavior may appear in school, home and in other places (O'Neill, Guenette\&Kitchenham, 2010).

As the self-esteem of children with learning disabilities is low, due to the ratio of school failure and rejection of those around them, they may begin to be withdrawn and closed on themselves, become aggressive, or have reduced motivation to learn (Glazzard, 2010).Having difficulty getting in each other's position, facing difficulties to form friendships with peers and prefer younger children, or cannot make friends or they cannot maintain them and remain isolated. Many times a child tries to nettle the attention of others by adopting an aggressive attitude, seeking membership in a group (Broomhead, 2014).

Apart from that specific learning difficulties usually associated with increased anxiety and low self-esteem, research (ONeil, Guenette\&Kitchenham, 2010) shows that children are less popular and generate more negative 
impression on others. He has also found that three out of four students with learning disabilities, have difficulties related to social skills (Doyle, 2004). Partnership, offering assistance, selfcontrol and communication are behaviors that facilitate the creation of relationships. But in the case of children with learning difficulties such features do not appear as they would have to start a social interaction with peers.

The student with learning disabilities tend to easily disrupted with emotional reactions that occur with waivers in student activities and procedures, without an obvious cause. Still, there are cases of students who develop a secondary defensive delinquent behavior as part of the learning process at school. This secondary defensive behavior operates and evolves to provide the student with difficulties to cope with the stress created by the consecutive ineffective efforts and frustration experienced in specific learning situations for many years.

The contribution of education in addressing social adjustment problems faced by children with learning disabilities is essential. The method of intervention may follow a child to school or special education, must have the support and active participation of parents (Broomhead, 2014).

The school welcomes students with or without learning difficulties without being ready to develop and implement programs, but also without being able to prepare them for learning activities ready to follow the subsequent learning process that will follow the general or special education. So the school readiness more often underestimated by the teacher because there is always adequate training or the requisite infrastructure to implement a multisensory, stepwise instruction, which will enable people with specific learning difficulties to improve their learning (Drakos \& Tsinarelis, 2011).

\section{Purpose}

In our study we intend to present evidence showing the importance of research in the teaching of social skills through a program to a student with learning disabilities and behavioral problems. It will also investigate the relationship between behavioral problems and difficulties in writing. We will approach the connection between selfesteem and the medical model of dyslexia. The growing importance of metacognitive skills for students with difficulties in writing, who develop strategies to assist in various areas of difficulty, will be considered as a method of teaching intervention (Schnitzer, Andries\&Lebeer, 2007). Finally, the introduction of facilitators of learning, the structure of space and environment where the learning process takes place (Doveston \& Keenaghan, 2006), the involvement of new technologies in teaching and placement in the core of our intervention, cognitive machines (e.g. shoe boxes) as a reference for the student, approaches will be the enterprise which will improve accessibility to school every day, in addition to increasing the student's self to the social challenges of life.

The correlation between the difficulties in writing and behavior problems (Undheim, Wichstram\&Sund, 2011) compared with individual protocols for students involved in teaching interventions within the inclusive classroom in Ionian Islands (King - Sears, 2008).

\section{Research Questions}

The basic assumption is that the student - reader has the opportunity to learn reading and utilizing visual perception, verbal memory, practice memory. Also to have the reading ability to recognize, read and not complicated known words, but also to understand multimodal texts to decode in different places and times in accordance with the requirements of the curriculum of the class.

We also assume that the improvement of the student's reading ability and increased confidence that will accompany her, will help to enhance social skills and reduce problem behaviors (Canney\& Byrne, 2006, O’Leary, Longmore\&Medcalf, 2014).

Specifically, three cases our research examines:

Case 1: Learning disabilities in writing coexist with externalized behavior problems.

Case 2: The externalized behavior problems prevent writing skills.

\section{Methodology}

Students with Learning Difficulties (DSM-IV-TR) encountered in school reality with low school performance. The methodology followed is the mixed method that mixes qualitative and quantitative approach based on the collection of qualitative and quantitative data. The target group will be employed during the survey consists of a student with learning disabilities and behavioral problems (boy, 11 years old) and adults (teachers, parents) who come into contact with him. The manner and time of employment of the target group identified by the practice, and case study student compound Cognitive Emotional and SocialDifficulties occurred in student with LD with participant observation for 140 hours. Specifically, the survey took place from Monday, November 11, 2013 to Wednesday, April 2 2014. The first part of the research methodology included the observation and the second part of the methodology for action. Each week, the frequency of meetings with our student ranged in 12-15 credit hours, depending on changes in the school program.

The qualitative data collected through the methodology of observation, methodology of intervention, specific instructional differentiation and interviews. The tools for the observations consist of systematic empirical observation of the student's "case study» (Key Study) in the general class of the school and the inclusive classroom. In particular we use records based on informal educational evaluation with Basic Skills Checklists (BSC) and baseline (performance and student behavior in accordance with the class and semester) areas: a) Learning readiness b) special educational needs as reflected in Curriculum Framework for Special Education, c) general learning difficulties and d) specific learning difficulties. The intervention methodology recorded self-observation and observation of student. Specific teaching variations recorded instructional objectives by developing differentiated annual, monthly, weekly, daily curriculum (Christakis, 2013) and behavior analysis.

It will include interviews lasting 15-20 minutes from all adults involved with the student to study the complex Cognitive Emotional and Social Difficulties. The content 
of the interviews will be based on specific themes concerning difficulties with the integration into the school community and teaching (Broomhead, 2014).

The quantitative data collected through the administration of a short questionnaire to all adults involved with the student's case study. Time employment of the target group defined in 3-4 months with possibility of adjusting depending on the research. The processing of data will be done by the method of multiple analyzes (multivariate analysis). For the use of research data requested by the investigator signed permission of parents of the student. Note that throughout the research, student's participation was voluntary and kept confidential.

\section{Findings}

Qualitative data demonstrated that learning difficulties in writing coexist with externalized behavior problems. In particular the informal educational assessment recorded changes between the initial, interim and final evaluation of the comments respectively. The externalized behavior problems prevent writing skills (second case) which demonstrated because the student presents three evaluative periods of lower performance, both in the writing skills and areas of behavior from the level of the class. Variations on Basic Skills Checklists (BSC) have more variation on line learning readiness to engage in dialogue, the rhythm and timing in auditory working memory and criteria that indicate the poor performance of the written word. The emotional organization is lower than the order level and specifically half semester, but the selfconfidence and interest in learning seemed to approach the baseline at the final evaluation which demonstrates the success of the intervention. Corresponding record was on the line and context in which it was initially weak in motor skills understanding and writing, and autonomy in the environment. In all the weak points improved at least a half semester which made the student more competitive and self- reliant in the courses of his class.

From the study of the qualitative data it seems that learning disorders co-exist with the behavioral problems regarding the frequency, the quantity and the quality. According to the first (blue line from), the intermediate (red line) and the final observation (red line) high divergences were found in the line of Learning Readiness (Picture 1) in the line of the Special Educational Needs according to the Curriculum of Special Education (Picture 2).

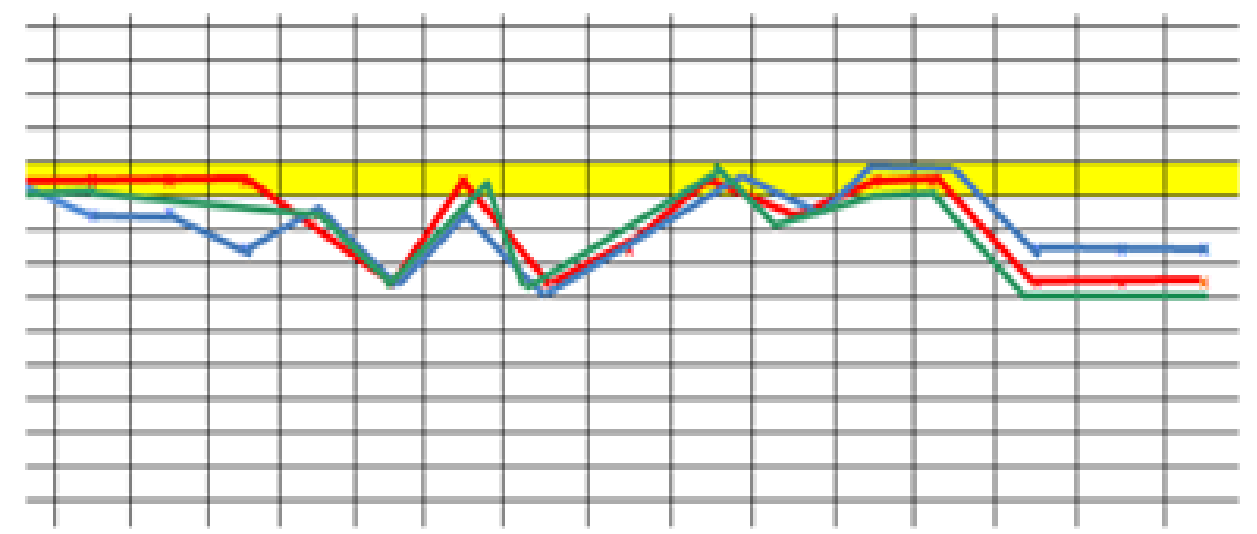

Picture 1. Changes in the Learning Readiness

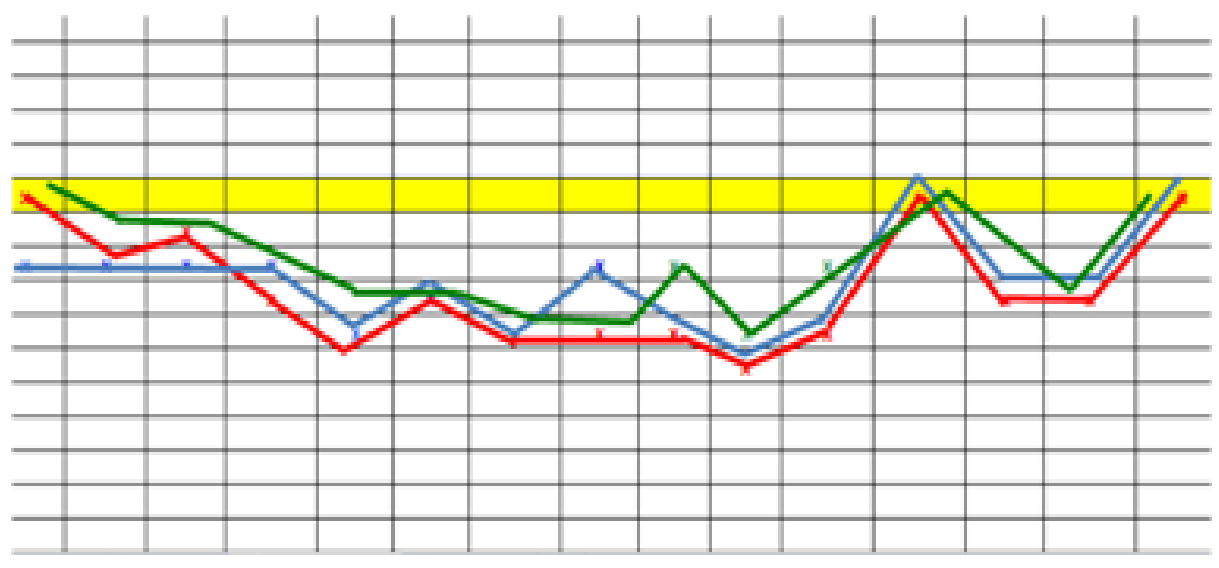

Picture 2. Changes in the Special Educational Needs according to the Curriculum of Special Education

The observations in the four areas show that divergences regarding learning difficulties are similar with these regarding behavioral problems. As a result, learning difficulties coexist with behavioral problems with the same frequency, quantity and quality. The 1st assumption is confirmed.

The link between reading comprehension difficulties and behavioral problems seems to be confirmed by the
Forms for Teaching Interaction. Here also we see how well the student is reinforced techniques and strategies of the writing process, while increasing their motivation for learning, by paying effort to increasingly greater intervals (5 minutes, 10 minutes, 15 minutes). The rise time of student engagement activities helped to gain self-control of his actions and more autonomy for school work.

Interview to adults 
The co-existence of the Learning Difficulties with the Behavioural Problems was affirmed through semistructured interview to three adults: mother, the schoolmaster and one teacher of the school. The answers show that the Specific Learning Difficulties of the student coexist with behavioral problems with the same frequency, quantity and quality. In addition, from the answers of the adults an enhancement both of the school performance and of her behavior have been found. In particular, Special Teaching Support faced some of the Learning Difficulties, raised her interest about the lesson and decreased her loneliness, her aggressiveness and her burst of anger. The interviews to the adults confirm the 1st and the 2nd assumption of the investigation.

According to the interviews, the teachers and the parents of the student proves that Targeted, Personal, Built, Membership Program of Special Education helped to improve the performance and behavior of both the classroom and in communication at home.

Based on the quantitative data could test different aspects of our hypothesis. Measurements of the questionnaire were directed more to the characteristics of student behavior, as tested by major adults (teachers, parents) have shown that the difficulties in communication has not been deeper but vary in surface events, which may change depending the circumstance (e.g. difficulty course, external stimuli, etc.).

Where the student seemed to have begun to understand how rules was the experimental process of social stories. The responses were recorded in the interim (every 15 minutes) questions of the three thematic questions of each story showed a consistent response to the relevance of the required teaching objective. Alongside through social stories confirmed the original learning objective "To improve the reading self-confidence and develop trust in written text production lines 5-10" with the use of visual conceptual facilitators and morphological structure of the word (Mowat, 2009, Casserly, 2013).

\section{Conclusions}

The results of our study showed that education and teaching special education interventions can help the student with reading difficulties and behavioral problems utilizing cognitive and metacognitive techniques such as social stories on individual intervention programs (Doyle, 2004, O'Leary, Longmore \& Medcalf, 2014).

Regarding the first empirical examination of the case, that learning difficulties in writing coexist with externalized behavior problems, we find that the case verified. In this case the emphasis was on "Writing" which worked specifically aimed at teaching "text production up to 10 lines." The texts and the words recorded were evaluated based on criteria related to the possibility of self-description of the spell, the recognition of the importance of spelling error in the analysis of the word and the text and morphological errors, syntax etc. It was found that difficulties in behavior work as a starting point to weaknesses in the writing skills (Christakis, 2013).

In case that the externalized behavior problems prevent writing skills, we find that the case verified. In this case, the emphasis of our work was to "understand the difficulties in Writing" by the student and included items listed in self-confidence, understanding the type of errors and other obstacles in the effort to write text etc. It was found that behavior problems and low self-esteem of the student prevented further improve the writing skills (Swinson, 2008, Glazzard, 2010).

\section{References}

[1] Achenbach, T. M., Ndetei, D. M., "Clinical models for child and adolescent behavioral, emotional and social problems", IACAPAP E-Textbook of Child and Adolescent Mental Health, 3, 2012.

[2] American Psychiatric Association (APA) Diagnostic and Statistical Manual of Mental Disorders, Forth Edition, (DSM-IV). Washington, DC: Author (1994).

[3] Broomhead, K., “'A clash of two worlds”; disjuncture between the norms and values held by educational practitioners and parents of children with behavioural, emotional and social difficulties", British Journal of Special Education, 41(2).136-150. 2014.

[4] Canney, C., Byrne, A., "Evaluating Circle Time as a support to social skills development-reflections on a journey in school-based research”, British Journal of Special Education, 33(1).19-24. 2006.

[5] Casserly, A. M., "The socio-emotional needs of children with dyslexia in different educational settings in Ireland”, Journal of Research in Special Educational Needs, 13(1).79-91. 2013.

[6] Christakis, K., Programs and teaching strategies, Diadrasi, Athens, 2013.

[7] Doveston, M., Keenaghan, M., "Improving classroom dynamics to support students' learning and social inclusion: A collaborative approach”, Support for Learning, 21(1). 5-11. 2006.

[8] Doyle, R., “A social development curriculum: Applying nurture group principles and practices to support socially and emotionally vulnerable children within mainstream classrooms", British Journal of Special Education, 31(1). 24-30. 2004.

[9] Drakos, G., D., Tsinarelis, G., A., Psychosocial aspects of school difficulties. Diadrasi, Athens, 2011.

[10] Glazzard, J., “The impact of dyslexia on pupils' self-esteem”, Support For Learning, 25 (2), 63-69. 2010.

[11] Hackett, L., Theodosiou, L., Bond, C., Blackburn, C., Spicer, F., Lever, R., "Mental health needs in schools for emotional, behavioural and social difficulties".British Journal of Special Education, 37(3).148-155. 2010.

[12] King - Sears, M. E., "Facts and fallacies: Differentiation and the general education curriculum for students with special educational needs”, Support for Learning, 23(2), 55-62. 2008.

[13] Mowat, J., "The inclusion of pupils perceived as having social and emotional behavioural difficulties in mainstream schools: A focus upon learning”, Support for Learning, 24(4), 159-169. 2009.

[14] O'Leary, N., Longmore, C., Medcalf, R., "The influence of occupational socialisation upon a teacher's interpretation and delivery of Teaching Games for Understanding to pupils experiencing social and emotional behavioural difficulties”, Support for Learning, 29(1), 57-75. 2014.

[15] O'Neill, L., Guenette, F., Kitchenham, A., ““Am I safe here and do you like me?’Understanding complex trauma and attachment disruption in the classroom", British Journal of Special Education, 37(4), 190-197. 2010.

[16] Schnitzer, G., Andries, C., Lebeer, J., "Usefulness of cognitive intervention programs for socio-emotional and behaviour problems in children with learning disabilities", Journal of Research in Special Educational Needs, 7(3), 161-171. 2007.

[17] Swinson, J., "Research section: The self-esteem of pupils in schools for pupils with social, emotional and behavioural difficulties: myth and reality”, British Journal of Special Education, 35(3), 165-172. 2008.

[18] Woolf, A., "Everyone Playing in Class: a group play provision for enhancing the emotional well-being of children in school”, British Journal of Special Education, 38(4), 178-190. 2011.

[19] Undheim, A., Wichstram, L., Sund, A., "Emotional and behavioral problems among school adolescents with and without reading difficulties as measured by the Youth Self-Report: A one-year follow-up study”, Scandinavian Journal of Educational Research, 55(3), 291-305. 2011. 